\title{
Real-World Data on Topical Therapies and Annual Health Resource Utilization in Hospitalized Swiss Patients with Ulcerative Colitis
}

\author{
Caroline Baehler $^{\mathrm{a}}$ Beat Brüngger ${ }^{\mathrm{a}}$ Eva Blozik $^{\mathrm{a}, \mathrm{b}}$ Stephan R. Vavricka ${ }^{\mathrm{c}, \mathrm{d}}$ \\ Alain M. Schoepfer ${ }^{\mathrm{e}}$ \\ ${ }^{a}$ Department of Health Sciences, Helsana Insurance Group, Zurich, Switzerland; ${ }^{b}$ Department of Medicine, \\ University Medical Centre Freiburg, Freiburg im Breisgau, Germany; ${ }^{c}$ Center for Gastroenterology and Hepatology, \\ Zurich, Switzerland; ${ }^{d}$ Gastroenterology and Hepatology, University Hospital Zurich, Zurich, Switzerland; \\ e Division of Gastroenterology and Hepatology, Centre Hospitalier Universitaire Vaudois/CHUV and University of \\ Lausanne, Lausanne, Switzerland
}

\section{Keywords}

Ulcerative colitis - Topical therapy · Rectal foam · Enema ·

5-Acetylsalicylic acid suppositories $\cdot$ Health care utilization

\begin{abstract}
Objectives: Topical treatment with aminosalicylates and/or budesonide was shown to be highly effective in patients with ulcerative colitis (UC), while reducing the likelihood of systemic adverse effects. However, previous research has shown that topical treatment is clearly underused. We aimed to evaluate the use of topical therapy in the real-world setting. Methods: This is an observational study based on claims data of 201 Swiss adult patients who were hospitalized for UC between 2012 and 2014 and who were then followed for 1 year. A variety of factors presumably associated with topical treatment were examined. Annual health care utilization (UC-related medications, diagnostic procedures, consultations, and rehospitalizations) of patients with versus without topical therapy was compared. Results: Of the 201 hospitalized UC patients, 82 (40.8\%) were treated with topical 5-acetylsalicylic acid (ASA) and/or topical rectal steroids. The main factors significantly and positively associated with receiving topical treatment were the use of topical treatment in the year prior to the hospitalization, receiving oral 5-ASA, and
\end{abstract}

living in an urban area. The mode of administration was further related to the language area. Patients with topical therapy significantly more often received other UC-related medications, such as combinations with systemic steroids. They significantly more often underwent colonoscopies and calprotectin measurements, and more often consulted a gastroenterologist in the follow-up, while there was no significant difference regarding rehospitalizations. Conclusions: Topical treatment is underused in patients with UC, which stands in contrast to the current European Crohn's and Colitis Organization guidelines. Patients' preferences and considerations need to be taken into account when prescribing medical therapy.

○ 2019 S. Karger AG, Basel

\section{Introduction}

Ulcerative colitis (UC) is a chronic relapsing inflammatory disorder of the colon. The etiology and pathophysiology of UC are not yet entirely understood, but immunological and environmental factors along with genetic susceptibility seem to mainly be responsible for the onset of UC $[1,2]$. The prevalence of UC is estimated to be around 260-500/100,000 in Western countries, and

\section{KARGER}

(c) 2019 S. Karger AG, Basel

E-Mail karger@karger.com

www.karger.com/iid
Alain M. Schoepfer

Division of Gastroenterology and Hepatology

Centre Hospitalier Universitaire Vaudois/CHUV and University of Lausanne

Rue du Bugnon 44, CH-1011 Lausanne (Switzerland)

E-Mail alain.schoepfer@chuv.ch 
prevalence seems to increase over time [3-5]. UC always involves the rectum and shows variable extension to the left side (left-sided colitis) or the entire colon (pancolitis). More than two thirds of UC patients in population-based studies exhibit only a proctitis/proctosigmoiditis or leftsided colitis whereas about one third of patients have extensive colitis at diagnosis [6-8]. 5-Aminosalicylic acid products (5-ASA; mesalazine or mesalamine) are considered to be first-line treatment in mild to moderate UC, irrespective of the disease localization [9-12]. In patients with proctitis or left-sided colitis, topical applications of 5-ASA as suppository, enema, or foam preparation were shown to be more effective compared with oral treatment $[9,13,14]$. Rectally administered 5-ASA was superior to rectal steroids, while rectal steroids are superior to placebo in this situation [15-19]. In contrast, a meta-analysis by Manguso and Balzano [20] found similar efficacy of rectal steroids (beclomethasone dipropionate) and topical 5 -ASA in patients with distal mild to moderate UC. Moreover, a previous study has found a beneficial effect of a combined oral and topical treatment also in patients with pancolitis [21]. Topical treatment (5-ASA and/or steroids) is associated with fewer side effects compared with a systemic administration, because rectally administered medications deliver a high dose of the active drug compound directly to the site of inflammation $[22,23]$. In the study by Seibold et al. [22], 334/790 (42.3\%) patients had a past topical treatment. Side effects were experienced in $7.5 \%$ of these patients, compared to $48.5 \%$ in patients with immunomodulators, $24 \%$ in patients with tumor necrosis factor (TNF) antagonists, and $13.1 \%$ in patients with oral 5-ASA [22]. However, low adherence levels result in ineffective disease control and an increased risk of acute flares $[24,25]$. The 5-ASA adherence rate was low in real-world practice, and it was significantly lower in topical therapy with enema compared with oral therapy [26]. Therefore, patients' preferences and considerations need to be taken into account when prescribing medical therapy. According to previous findings, patients clearly preferred foam preparations, with respect to steroids, as well as with respect to 5-ASA medications $[27,28]$.

In summary, topical treatment was shown to be highly effective, while reducing the likelihood of systemic adverse effects. Especially patients with proctitis, rectosigmoiditis, or left-sided colitis could benefit from topical therapy. However, previous research has shown that topical treatment is clearly underused in a cohort of Swiss patients who were mainly treated in a university hospital setting and in a US setting, respectively [22,29]. As of yet, little is known about the frequency of topical treatment and the factors associated with topical therapy in the reallife setting.

We therefore aimed to examine the proportion of UC patients treated with topical therapies, the mode of administration of topical therapy, as well as the factors associated with topical treatment in a real-world setting. Moreover, we aimed to compare the utilization of various health care resources (UC-related medications, diagnostic procedures, consultations, and rehospitalizations) in the year following UC-related hospitalization in patients with versus without topical therapy.

\section{Methods}

Study Design and Study Population

This is an observational study based on claims data of the Helsana Group, one of the leading insurance companies in Switzerland. Helsana provides insurance coverage for about 1.2 million inhabitants in Switzerland which roughly corresponds to $15 \%$ of the entire Swiss population (which currently counts 8 million inhabitants). Patients hospitalized for UC were followed for 1 year, thereby comparing patients with and without topical therapy with 5-ASA and/or rectal steroids. We focused on UC patients who required a hospitalization as only in this population the UC diagnosis is coded as such whereas it would be only approximative in UC outpatients never requiring a hospitalization (see methods below) $[30,31]$. The year before the index hospitalization was also included in order to examine the prestationary medical therapies. The study population consists of 256 adult UC patients who were hospitalized with a main diagnosis of UC between January 1st, 2012, and December 31st, 2014. The main diagnosis of UC means that the main reason for the hospitalization was the underlying UC. Fourteen $(5.4 \%)$ patients aged 17 years and younger, 14 patients who died during the follow-up, as well as $27(10.5 \%)$ patients with missing data (i.e., patients living abroad, lump sums used for reimbursement of nursing home residents, or no full insurance coverage at Helsana Group for the observation time of 2 years) were excluded. As such, a total of 201 UC patients were included for analysis.

The present study falls outside the scope of the Swiss Federal Act on Research involving Human Beings (Human Research Act), as the study is retrospective and based on anonymized routine administrative health care claims data. Therefore, in accordance with the Swiss national ethical and legal regulations, no patient informed consent and no further ethics approval were needed.

\section{Measures}

The organization of the Swiss health care system has been described in a recent publication [31]. In Switzerland, a "diagnosisrelated group" system was introduced in 2012, which refers to ICD-10 codes and applied procedures. As such, UC patients were identified using the directional ICD-10 code K51. Main outcome variables comprise the proportion of patients with topical therapy, as well as the application form of the topical treatment. In addition, the need for further UC-related medications and/or combination therapies, the rate of rehospitalizations and disease-related rehos- 
Table 1. Characteristics of the study population

\begin{tabular}{|c|c|c|c|c|}
\hline Characteristics & Total & $\begin{array}{l}\text { No topical } \\
\text { treatment }\end{array}$ & $\begin{array}{l}\text { Topical } \\
\text { treatment }\end{array}$ & $p$ \\
\hline Number & 201 & $119(59.2 \%)$ & $82(40.8 \%)$ & \\
\hline Female sex & $111(55.2 \%)$ & $71(59.7 \%)$ & $40(48.8 \%)$ & ns \\
\hline $\begin{array}{l}\text { Age } \\
18-40 \text { years } \\
41-60 \text { years }\end{array}$ & $\begin{array}{l}53(26.4 \%) \\
46(22.9 \%)\end{array}$ & $\begin{array}{l}25(21.0 \%) \\
26(21.8 \%)\end{array}$ & $\begin{array}{l}28(34.1 \%) \\
20(24.4 \%)\end{array}$ & ns \\
\hline$>60$ years & $102(50.7 \%)$ & $68(57.1 \%)$ & $34(41.5 \%)$ & \\
\hline Language area: German & $168(83.6 \%)$ & $100(84.0 \%)$ & $68(82.9 \%)$ & ns \\
\hline Language area: French/Italian & $33(16.4 \%)$ & $19(16.0 \%)$ & $14(17.1 \%)$ & \\
\hline Type of residence (urban area) & $155(77.1 \%)$ & $84(70.6 \%)$ & $71(86.6 \%)$ & 0.010 \\
\hline Chronic condition (excl. UC; 0-1) & $91(45.3 \%)$ & $45(37.8 \%)$ & $46(56.1 \%)$ & 0.007 \\
\hline 2-4 chronic conditions & $65(32.3 \%)$ & $39(32.8 \%)$ & $26(31.7 \%)$ & \\
\hline$\geq 5$ chronic conditions & $45(22.4 \%)$ & $35(29.4 \%)$ & $10(12.2 \%)$ & \\
\hline Home care nursing dependency & $33(16.4 \%)$ & $22(18.5 \%)$ & $11(13.4 \%)$ & ns \\
\hline \multicolumn{5}{|l|}{ Health insurance plan } \\
\hline Managed care & $93(46.3 \%)$ & $51(42.9 \%)$ & $42(51.2 \%)$ & ns \\
\hline Higher deductible & $18(9.0 \%)$ & $7(5.9 \%)$ & $11(13.4 \%)$ & ns \\
\hline Supplementary hospital insurance & $36(17.9 \%)$ & $25(21.0 \%)$ & $11(13.4 \%)$ & ns \\
\hline Left-sided colitis ${ }^{\mathrm{a}}$ & $68(33.8 \%)$ & $40(33.6 \%)$ & $28(34.1 \%)$ & ns \\
\hline Previous topical therapy & $63(31.3 \%)$ & $21(17.6 \%)$ & $42(51.2 \%)$ & $<0.001$ \\
\hline Surgery at index hospitalization & $15(7.5 \%)$ & $10(8.4 \%)$ & $5(6.1 \%)$ & ns \\
\hline
\end{tabular}

$p$ values, assigning the differences between UC patients with and without topical therapy, were calculated using Fisher's exact test for dichotomous variables and the $\chi^{2}$ test for categorical variables. ns, not significant. ${ }^{a}$ Including rectosigmoiditis, proctitis, and left-sided colitis.

pitalizations, the number of face-to-face consultations by primary care physicians, gastroenterologists and/or other specialists, as well as the number of diagnostic procedures (computed tomography scans, magnetic resonance imaging, X-ray, ultrasound, colonoscopy, and calprotectin measurement) in patients with versus without topical therapy were assessed. Further UC-related medications include: oral 5-ASA (mesalazine and sulfasalazine), immunomodulators (methotrexate, azathioprine, and mercaptopurine), TNF antagonists (infliximab, adalimumab, golimumab), integrin inhibitors (vedolizumab, that got its first marketing approval in Switzerland in January 2015), and/or steroids (prednisone, oral budesonide).

We analyzed the following factors regarding their association with the use of topical therapies: topical 5-ASA and/or rectal steroid therapy in the year prior to the index hospitalization, patient characteristics (age group: 18-40, 41-60, and $\geq 61$ years, sex, and additional chronic conditions), the type of patients' health insurance plan (managed care, deductible class, supplementary insurance), and regional factors (type of residence and language area).

Additional chronic conditions were identified based on the Anatomical Therapeutic Chemical classification system, using an updated measure of the Pharmacy-Based Cost Group model by $\mathrm{Hu}$ ber et al. [32]. Twenty-one additionally treated chronic conditions were considered: acid-related disorders, bone diseases (osteoporosis), cancer, cardiovascular diseases (incl. hypertension), dementia, diabetes mellitus, epilepsy, glaucoma, gout/hyperuricemia, HIV, hyperlipidemia, iron deficiency anemia, migraines, pain, Parkinson's disease, psychological disorders (sleep disorders, de- pression), psychoses, respiratory illness (asthma, COPD), rheumatologic conditions, thyroid disorders, and tuberculosis.

\section{Statistical Analysis}

Descriptive statistics were used to evaluate differences between the characteristics of UC patients with and without topical treatment using Fisher's exact test for dichotomous variables, Wilcoxon's rank-sum test for continuous variables, and the $\chi^{2}$ test for categorical variables. Data are presented as percentages for categorical variables and as medians and interquartile ranges (showing the 1st and 3rd quartiles) for continuous variables. Logistic regression modeling was applied to examine factors that are associated with topical treatment and its different application forms. Multinomial logistic regression analysis was performed to determine the impact of sociodemographic, regional, and treatment-related variables on the odds of having no topical treatment, one mode of topical administration, or more than one mode of administration [33]. A threshold for statistical significance of $p=0.05$ (two-sided) was utilized.

\section{Results}

\section{Topical Treatment, Mode of Administration, and Its} Associated Factors

The mean age of the study population was $54.3( \pm 20.4)$ years, and $44.8 \%$ were males. Descriptive statistics of the 
Table 2. Topical treatment according to disease location in the year after hospitalization

\begin{tabular}{lccc}
\hline Disease location & Total & $\begin{array}{c}\text { No topical } \\
\text { treatment }\end{array}$ & $\begin{array}{l}\text { Topical } \\
\text { treatment }\end{array}$ \\
\hline Number & 201 & $119(59.2 \%)$ & $82(40.8 \%)$ \\
Proctitis & $10(5.0 \%)$ & $2(1.7 \%)$ & $8(9.8 \%)$ \\
Rectosigmoiditis & $14(7.0 \%)$ & $6(5.0 \%)$ & $8(9.8 \%)$ \\
Left-sided colitis & $44(21.9 \%)$ & $32(26.9 \%)$ & $12(14.6 \%)$ \\
Extensive & & & \\
$\quad$ colitis/pancolitis & $47(23.4 \%)$ & $30(25.2 \%)$ & $17(20.7 \%)$ \\
Location not specified & $86(42.8 \%)$ & $49(41.2 \%)$ & $37(45.1 \%)$ \\
\hline
\end{tabular}

Table 3. Logistic regression modeling identifying sociodemographic and treatment-related factors associated with receiving topical treatment $(n=201)$ in the year after index hospitalization

\begin{tabular}{lll}
\hline & OR $(95 \%$ CI $)$ & $p$ \\
\hline Age $>60$ years & 1.000 & \\
Age 18-40 years & $0.993(0.368-2.663)$ & $\mathrm{ns}$ \\
Age 41-60 years & $1.418(0.578-3.467)$ & $\mathrm{ns}$ \\
Female sex & $0.628(0.298-1.307)$ & $\mathrm{ns}$ \\
Language area: French/Italian & $0.799(0.307-2.027)$ & $\mathrm{ns}$ \\
Type of residence (urban area) & $2.642(1.124-6.582)$ & 0.030 \\
Managed care & $1.048(0.515-2.118)$ & $\mathrm{ns}$ \\
Supplementary hospital insurance & $0.505(0.189-1.287)$ & $\mathrm{ns}$ \\
Chronic condition (excl. UC; 0-1) & 1.000 & \\
$\quad$ 2-4 chronic conditions & $0.695(0.293-1.637)$ & $\mathrm{ns}$ \\
$\quad$ 25+ chronic conditions & $0.460(0.152-1.320)$ & $\mathrm{ns}$ \\
Left-sided colitis & $1.483(0.705-3.161)$ & $\mathrm{ns}$ \\
Previous topical therapy & $4.791(2.230-10.751)$ & $<0.001$ \\
5-ASA, oral & $3.164(1.497-6.892)$ & 0.003 \\
Thiopurines & $1.063(0.423-2.632)$ & $\mathrm{ns}$ \\
TNF antagonists & $2.238(0.782-6.725)$ & $\mathrm{ns}$ \\
Steroids, systemic & $1.271(0.544-2.951)$ & $\mathrm{ns}$ \\
\hline
\end{tabular}

OR, odds ratio; CI, confidence interval; ns, not significant. Akaike information criterion $=240.49$.

characteristics of patients with versus without topical treatment in the year after the hospitalization are presented in Table 1. Of the 201 hospitalized adult patients with a main diagnosis of UC, 82 (40.8\%) were treated with topical 5-ASA and/or topical rectal steroids (Fig. 1). Ninety percent $(74 / 82)$ of these patients had a combined oral and topical treatment. Looking solely at the 68 patients with rectosigmoiditis, proctitis or left-sided colitis, the proportion of patients with topical treatment hardly changed (41.2\% with topical treatment, Fig. 1). Topical treatment in the year prior to the UC-related hospitalization was
Table 4. Drugs and application forms used for topical treatment $(n=82)$

\begin{tabular}{llcl}
\hline $\begin{array}{l}\text { Mode of } \\
\text { treatment }\end{array}$ & 5-ASA & $\begin{array}{l}\text { Steroids } \\
\text { (budesonide) }\end{array}$ & Total \\
\hline Enema & $28(34.1 \%)$ & $6(7.3 \%)$ & $32(39.0 \%)$ \\
Foam & $27(32.9 \%)$ & $30(36.6 \%)$ & $46(56.1 \%)$ \\
Suppositories & $31(37.8 \%)$ & - & $31(37.8 \%)$ \\
\hline Total & $69(84.1 \%)$ & $33(40.2 \%)$ & $82(100 \%)$ \\
\hline
\end{tabular}

The total numbers may be lower than the sum of each application form as patients may use more than one mode of administration.

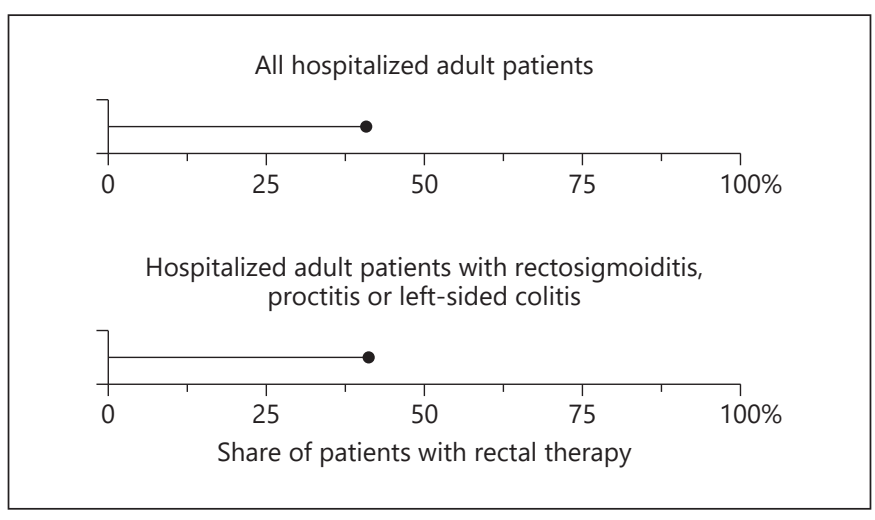

Fig. 1. Proportion of UC patients with topical therapy in the year after index hospitalization.

found in 63/201 (31.3\%) patients, whereby 32 patients received 5-ASA, 12 patients received steroids, and 19 patients were treated with both drugs. Patients with topical therapy more often lived in an urban area and had fewer additional chronic conditions (Table 1). The proportions of patients with topical treatment by disease localization are shown in Table 2. In summary, 68 (33.8\%) of UC patients suffered from a proctitis, a rectosigmoiditis or a left-sided colitis.

In the logistic regression model, the main factors significantly associated with receiving topical treatment were the use of topical treatment in the year prior to the disease-related hospitalization, receiving oral 5-ASA, and living in an urban area (Table 3 ). In contrast, sociodemographic factors such as age and sex, as well as additional chronic conditions did not seem to play an important role in the multivariate model. 
Table 5. Medications and drug combinations in patients treated with and without topical therapy during the 12-month follow-up $(n=201)$

\begin{tabular}{|c|c|c|c|c|}
\hline Medications & Total & $\begin{array}{l}\text { No topical } \\
\text { treatment }\end{array}$ & $\begin{array}{l}\text { Topical } \\
\text { treatment }\end{array}$ & $p$ \\
\hline Number & 201 & $119(59.2 \%)$ & $82(40.8 \%)$ & \\
\hline 5-ASA orally & $109(54.2 \%)$ & $48(40.3 \%)$ & $61(74.4 \%)$ & $<0.001$ \\
\hline Thiopurines & $69(34.3 \%)$ & $31(26.1 \%)$ & $38(46.3 \%)$ & 0.004 \\
\hline TNF antagonists & $42(20.9 \%)$ & $18(15.1 \%)$ & $24(29.3 \%)$ & 0.021 \\
\hline Systemic steroids & $128(63.7 \%)$ & $66(55.5 \%)$ & $62(75.6 \%)$ & 0.004 \\
\hline 5-ASA + thiopurines & $54(26.9 \%)$ & $19(16.0 \%)$ & $35(42.7 \%)$ & $<0.001$ \\
\hline 5-ASA + biologics & $32(15.9 \%)$ & $11(9.2 \%)$ & $21(25.6 \%)$ & 0.003 \\
\hline Thiopurines + biologics & $24(11.9 \%)$ & $5(4.2 \%)$ & $19(23.2 \%)$ & $<0.001$ \\
\hline Thiopurines + biologics +5 -ASA & $20(10.0 \%)$ & $4(3.4 \%)$ & $16(19.5 \%)$ & $<0.001$ \\
\hline Systemic steroids + 5-ASA & $149(74.1 \%)$ & $75(63.0 \%)$ & $74(90.2 \%)$ & $<0.001$ \\
\hline Systemic steroids + thiopurines & $133(66.2 \%)$ & $69(58.0 \%)$ & $64(78.0 \%)$ & 0.003 \\
\hline Systemic steroids + biologics & $132(65.7 \%)$ & $68(57.1 \%)$ & $64(78.0 \%)$ & 0.002 \\
\hline
\end{tabular}

$p$ values, assigning the differences between UC patients with and without topical therapy, were calculated using Fisher's exact test.

Fig. 2. Proportion of patients with topical therapy and respective application form in the year after index hospitalization.

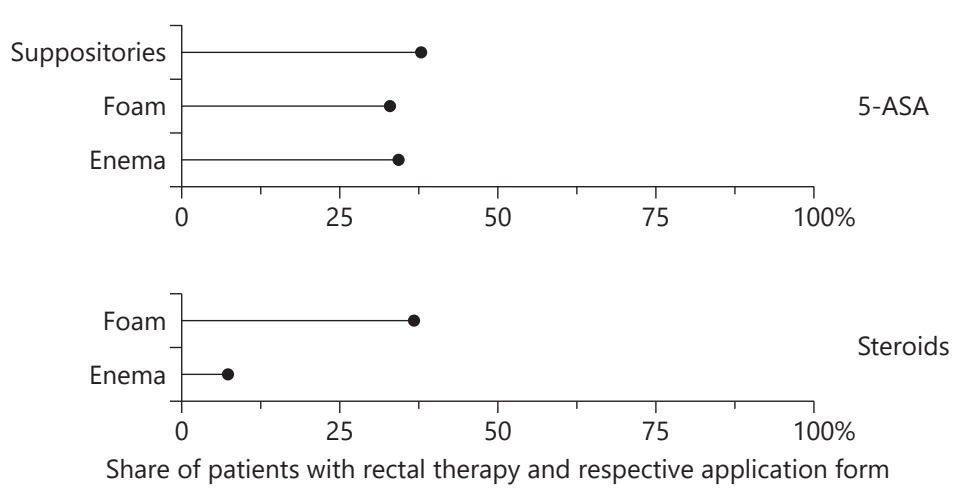

Overall, foam was the most prevalent application form in topical therapy (Table 4; Fig. 2). In logistic regression models, looking at factors associated with the mode of administration of topical treatment, pretreatment with topical 5-ASA and/or steroids was significantly and positively associated with receiving foam $(\mathrm{OR}=2.67$ [1.18$6.22], p=0.020)$ or suppositories $(\mathrm{OR}=5.16$ [1.97-14.50], $p=0.001$ ), but not enema in the follow-up period. Receiving oral 5-ASA was also positively associated with taking foam $(\mathrm{OR}=2.75$ [1.17-6.87], $p=0.024)$ and/or enema $(\mathrm{OR}=6.99$ [2.29-25.56], $p=0.001)$ in the 1-year followup. Living in the French or Italian region was significantly and positively associated with receiving 5-ASA foam $(\mathrm{OR}=3.29[1.06-10.19], p=0.037)$, and significantly and negatively associated with 5-ASA enema use $(\mathrm{OR}=0.10$ [0.01-0.52], $p=0.017)$. Regarding disease location, leftsided colitis was only significantly related to foam use $(\mathrm{OR}=2.52$ [1.13-5.73], $p=0.025)$.

In the population with topical treatment, $23(28.0 \%)$ patients used more than one mode to administer medications. In the multinomial logistic regression model, controlling for age group, sex, further chronic conditions, disease location, language area, and further UC-related medications, patients with prior topical treatment had 4.6 times higher odds of receiving topical treatment $(\mathrm{CI}=$ 1.99-10.55), and 6 times higher odds of using more than one mode of administration ( $\mathrm{CI}=1.97-18.20)$. Treatment with oral 5-ASA was also associated with higher 
Table 6. Diagnostic procedures in patients treated with and without topical therapy during the 12-month followup after hospitalization $(n=201)$

\begin{tabular}{lcccc}
\hline Diagnostic procedures & Total & $\begin{array}{l}\text { Nontopical } \\
\text { treatment }\end{array}$ & $\begin{array}{l}\text { Topical } \\
\text { treatment }\end{array}$ & $p$ \\
\hline Number & 201 & $119(59.2 \%)$ & $82(40.8 \%)$ & $\mathrm{ns}$ \\
Computer tomography & $27(13.4 \%)$ & $15(12.6 \%)$ & $12(14.6 \%)$ & 0.017 \\
Abdominal magnetic resonance imaging & $10(5.0 \%)$ & $2(1.7 \%)$ & $8(9.8 \%)$ & $\mathrm{ns}$ \\
X-ray & $4(2.0 \%)$ & $1(0.8 \%)$ & $3(3.7 \%)$ & $\mathrm{ns}$ \\
Abdominal ultrasound & $66(32.8 \%)$ & $33(27.7 \%)$ & $33(40.2 \%)$ & 50.001 \\
Colonoscopy & $101(50.2 \%)$ & $45(37.8 \%)$ & $56(68.3 \%)$ & 0.002 \\
Fecal calprotectin & $46(22.9 \%)$ & $18(15.1 \%)$ & $28(34.1 \%)$ & \\
\hline
\end{tabular}

$p$ values, assigning the differences between UC patients with and without topical therapy, were calculated using Fisher's exact test. ns, not significant.

Table 7. Number of consultations in patients treated with and without topical therapy during the 12-month follow-up $(n=201)$

\begin{tabular}{lcccl}
\hline Face-to-face consultations & Total & $\begin{array}{l}\text { No topical } \\
\text { treatment }\end{array}$ & $\begin{array}{l}\text { Topical } \\
\text { treatment }\end{array}$ & $p$ \\
\hline Number & 201 & $119(59.2 \%)$ & $82(40.8 \%)$ & \\
Total consultations & $23.0(15.0-35.0)$ & $21.0(13.5-31.0)$ & $26.0(17.3-37.0)$ & 0.013 \\
By primary care physicians & $9.0(2.0-14.0)$ & $8.0(1.0-13.0)$ & $9.5(4.0-17.0)$ & $\mathrm{ns}$ \\
By gastroenterologists & $9.0(3.0-14.0)$ & $7.0(2.0-11.0)$ & $12.0(4.3-18.0)$ & 0.001 \\
By other specialists & $4.0(1.0-11.0)$ & $4.0(1.0-10.5)$ & $4.5(1.0-11.0)$ & $\mathrm{ns}$ \\
\hline
\end{tabular}

Results are expressed as medians with interquartile ranges in parentheses, except number. $p$ values, assigning the differences between UC patients with and without topical therapy, were calculated using Wilcoxon's ranksum test. ns, not significant.

odds of receiving topical treatment $(\mathrm{OR}=3.20, \mathrm{CI}=1.42-$ 7.23). However, due to the wide confidence interval, results need to be interpreted with caution.

\section{Health Care Utilization during the 1-Year Follow-Up}

Patients with topical therapy significantly more often received all other UC-related medications, such as combinations with systemic steroids (Table 5). Integrin inhibitors were only found in 1 patient who additionally received TNF antagonists and topical treatment. Patients with topical treatment were also more likely to receive a higher number of further UC-related drug prescriptions, notably for systemic steroids and oral 5-ASA (results not shown).

Patients with topical therapy significantly more often underwent diagnostic procedures, especially colonoscopies and measurements of fecal calprotectin (Table 6). Pa- tients treated with topical therapy had a significantly higher median number of face-to-face consultations, whereby the biggest difference was found for consultations with gastroenterologists (Table 7).

We found no significant difference between patients treated with and without topical therapy regarding rehospitalizations (ever had a rehospitalization or the number of rehospitalizations) in the year following the index hospitalization (Table 8). More than one third of all UC patients had at least one rehospitalization within 12 months after the index hospitalization. In the multivariate logistic regression model, there was again no significant difference regarding rehospitalization between patients with and without topical therapy, when controlling for age group, sex, further chronic conditions, disease location, language area, urbanity, patients' health insurance plan, and further UC-related medications (results not shown). 
Table 8. Rehospitalizations in patients treated with and without topical therapy during the 12-month follow-up

\begin{tabular}{lcccc}
\hline Rehospitalization & Total & $\begin{array}{l}\text { No topical } \\
\text { treatment }\end{array}$ & $\begin{array}{l}\text { Topical } \\
\text { treatment }\end{array}$ & $p$ \\
\hline Rehospitalization & $74(36.8 \%)$ & $44(37.0 \%)$ & $30(36.6 \%)$ & $\mathrm{ns}$ \\
Number of rehospitalizations (median/IQR) $_{\text {Surgery }^{1}}^{0(0-1.0)}$ & $0(0-1.0)$ & $0(0-1.0)$ & $\mathrm{ns}$ \\
Disease-related surgery $^{1}$ & $28(37.8 \%)$ & $24(54.5 \%)$ & $4(13.3 \%)$ & $\mathrm{na}$ \\
\hline
\end{tabular}

$p$ values, assigning the differences between UC patients with and without topical therapy, were calculated using Fisher's exact test for dichotomous variables and Wilcoxon's rank-sum test for continuous variables. ns, not significant; na, not applicable; IQR, interquartile range. ${ }^{1}$ In those 74 patients with at least 1 rehospitalization.

\section{Discussion}

In this study we present population-based real-life data on the use of topical therapies and health care consumption in Swiss UC patients who were followed for 1 year after an index hospitalization. Our analysis contains several clinically relevant messages. First, only $41 \%$ of UC patients (all disease locations) were treated with topical 5-ASA and/or topical rectal steroids. Second, topical treatment in the year prior to the UC-related hospitalization was found in only $31 \%$ of patients. Third, the main factors significantly and positively associated with receiving topical treatment were the use of topical treatment in the year prior to the hospitalization, receiving oral 5-ASA, and living in an urban area. Fourth, patients with topical therapy significantly more often received other UC-related drugs, which points towards a severer disease pattern when compared to UC patients without topical therapies. And fifth, patients with topical therapies significantly more often consumed health care compared to patients without topical therapies.

Based on the solid literature evidence, the current European Crohn's and Colitis Organization guidelines state that mild to moderately active UC (proctitis, left-sided colitis, and extensive colitis) should be treated with local 5-ASA therapy (suppositories or enema, respectively) plus a combination of oral 5-ASA products [34]. The guidelines further state that patients with severe UC should be admitted to hospital for intensive treatment [35]. Topical treatment was shown to be highly effective, while reducing the likelihood of systemic adverse effects. In a follow-up study of a median of 6 years, combined oral and rectal treatment was clearly superior to oral treatment alone in 84 UC patients, with no dropouts or side effects in either group [35]. Patients with a combined therapy had a significant reduction in the incidence of relapses [36]. Moreover, patients with a combined oral and rectal therapy had lower overall costs, because the higher drug costs were offset by $48 \%$ lower costs due to the reduction in relapses and due to no accruing costs for hospitalizations in the follow-up [36]. Our real-life data document an important underuse of local therapy that stands in clear contrast to the therapeutic guidelines [35]. Patients under topical treatment more often received other UC-related medications, had more endoscopies, and had more frequently consultations by gastroenterologists. Based on these observations we hypothesize that topical therapy was applied in patients with severer disease in combination with systemic steroids and biologics to more rapidly achieve a clinical response or remission, respectively. Of note, a recent paper by Singh et al. [36] showed that continuation of 5-ASA in moderate-to-severe UC patients who were escalated to TNF antagonists did not improve clinical outcomes. Our data on the frequency of topical treatments are in accordance with data from Seibold et al. [22], who showed that 334/790 (42.3\%) of UC patients had a past topical treatment. The main difference between the two studies is that in the Seibold study UC patients were recruited in $80 \%$ of cases by gastroenterologists working in hospital while as in our study the results can be regarded as a population-based selection of hospitalized patients [12]. There might exist several reasons from the side of the prescribing physicians and from the patients' side as well to explain the underuse of local therapies in UC patients. First of all, it is possible that prescribing physicians are not sufficiently aware of the data demonstrating the efficacy and safety of the different forms of local therapy in UC. It is also possible that physicians, despite their knowledge of the data, fail to transport the important information onto the patient and empower them to use local therapies. On the patient's side it is well possible that there exist psychosocial barri- 
ers that limit the use of local treatment. We claim that physicians prescribing local therapy should be proactive in informing patients regarding the efficacy and safety, but also take into account the patients' preferences and considerations as low adherence levels result in ineffective disease control [24]. Several studies have evaluated the patient's view regarding local therapy in UC. Even though steroid enemas and steroid foam were both shown to be effective in the treatment of distal UC, patients clearly preferred foam preparations [27]. Due to their higher volume, enemas are often less well tolerated than foam during acute flares and may cause pain and discomfort. In 233 patients with UC, 5-ASA foam was better accepted than 5-ASA enema, because it was more comfortable, interfered less with daily living and was well tolerated [28]. Treatment with 5-ASA suppositories was more effective and found to be more practical in patients with distal UC in comparison to treatment with hydrocortisone foam [37]. The superiority of 5-ASA enemas and suppositories over topical steroids or oral therapies was confirmed by the results of a meta-analysis by Cohen and colleagues [17]. We conclude that every prescribing physician should be aware about the data regarding topical therapies and communicate them in a proactive way to the concerned patients. Treatment decisions should be made on a joint basis between prescribing physician and patient in order to achieve a patient empowerment with consecutively better adherence rates to the prescribed treatment which ultimately results in better clinical outcomes [38, 39].

According to our analysis, $50.2 \%$ of all patients had a colonoscopy within 1 year after the disease-related hospitalization, whereby the proportion was significantly higher in patients with topical treatment. Other disease-monitoring tools such as measurement of fecal calprotectin were also significantly more frequently found in UC patients with topical treatment. We assume that UC patients with topical disease represented a cohort characterized by severer disease activity compared to patients without local treatment and therefore indeed were in need of more frequently applied monitoring of endoscopic activity. More than one third of the patients of our cohort were rehospitalized within 1 year after the index hospitalization without detecting a difference between patients with and without topical treatment. A total of $18 \%$ of rehospitalized patients underwent UC-related surgery; again no difference was found between patients with and without topical treatment. In a Canadian study, $18.5-20.3 \%$ of UC patients were rehospitalized at least once per year, whereby, $55 \%$ had to undergo a major surgery [40].
Our population-based study has several strengths and also some limitations. The analyses are based on health insurance claims data that cover a broad range of highly reliable and comprehensive information on in- and outpatient care. These data were not collected by means of self-reports, and results were therefore not distorted due to recall bias. As a first limitation, we were not able to consider medications applied during hospitalizations. Additionally, variables such as disease activity, disease duration, disease evolution, as well as patients' preferences were not assessed [41]. The study looks at health care utilization in the year following UC-related hospitalization, independently of the reason for use. As such, the entire health care utilization may not be necessarily related to UC treatment. Secondly, as a limitation that is inherent to our study methodology, we had to focus on the population of UC patients in need of a hospitalization. Our target population might be characterized by a disease course that is severer when compared to UC patients not in need of a hospitalization. As such, all results are valid only for inpatients with UC and can therefore not be generalized to the entire population of UC patients in Switzerland. Third, the data we present in this paper are specific for Switzerland and cannot be generalized to other countries.

In conclusion, our real-life data show that topical therapies are clearly underused in UC patients which stands in sharp contrast with the current European Crohn's and Colitis Organization guidelines on the management of UC. A good adherence to local therapies in UC patients has shown to save health care costs by reducing the risk of flares and hospitalizations. Factors on the physicans' and patients' side hampering the use of local therapies need to be further evaluated.

\section{Acknowledgments}

We are grateful to Sonja Wehrle, Sonja Aerne, and Mikaël Thomas for their helpful support in coding inpatient and outpatient treatments.

\section{Statement of Ethics}

According to the Swiss Federal Law on data protection, this study was exempted from ethics committee approval as all data were anonymized, retrospective, pre-existing, and de-identified in order to protect the privacy of patients, physicians, and hospitals. 


\section{Availability of Data and Material}

Individual data cannot be made fully available because the study is based on claims data of the Helsana Group, the owner of the data. Thus, data underlie data protection and privacy restrictions. These restrictions prohibit us from sharing the collected data.

\section{Disclosure Statement}

A.M.S. consulted and received speaker's honoraria from Abbvie, UCB, Falk, MSD, Tillotts, Vifor, Pfizer, Ferring, Receptos, and Takeda. S.R.V. consulted and received speaker's honoraria from Abbvie, UCB, Falk, MSD, Tillots, Vifor, Pfizer, Takeda, and Ferring. The other authors have no competing interests to declare.

\section{Funding Sources}

This study was funded by Vifor Pharma (Switzerland). The sponsor reviewed, discussed and approved the protocol (VP-IISSAL-01.2017). Conduction, analysis, and interpretation of the data, preparation, and submission of the manuscript were solely in the responsibility of the authors, without any obligations to the sponsor.

\section{Author Contributions}

A.M.S., S.R.V., B.B., O.R., E.B., and C.B. conceptualized and designed the study. C.B. and B.B. performed the statistical analysis. All authors contributed to data interpretation and manuscript writing and had full access to all data in the study. All authors read and approved the final manuscript.

\section{References}

1 Cleynen I, Boucher G, Jostins L, Schumm LP, Zeissig S, Ahmad T, et al.; International Inflammatory Bowel Disease Genetics Consortium. Inherited determinants of Crohn's disease and ulcerative colitis phenotypes: a genetic association study. Lancet. 2016 Jan; 387(10014):156-67.

2 Conrad K, Roggenbuck D, Laass MW. Diagnosis and classification of ulcerative colitis. Autoimmun Rev. 2014 Apr-May; 13(4-5): 463-6.

3 Kappelman MD, Moore KR, Allen JK, Cook SF. Recent trends in the prevalence of Crohn's disease and ulcerative colitis in a commercially insured US population. Dig Dis Sci. 2013 Feb;58(2):519-25.

4 Hein R, Köster I, Bollschweiler E, Schubert I. Prevalence of inflammatory bowel disease: estimates for 2010 and trends in Germany from a large insurance-based regional cohort. Scand J Gastroenterol. 2014 Nov;49(11): 1325-35.

5 Molodecky NA, Soon IS, Rabi DM, Ghali WA, Ferris M, Chernoff G, et al. Increasing incidence and prevalence of the inflammatory bowel diseases with time, based on systematic review. Gastroenterology. 2012 Jan;142(1): 46-54.e42.

6 Solberg IC, Lygren I, Jahnsen J, Aadland E, Høie O, Cvancarova M, et al.; IBSEN Study Group. Clinical course during the first 10 years of ulcerative colitis: results from a population-based inception cohort (IBSEN Study). Scand J Gastroenterol. 2009;44(4): 431-40.

7 Magro F, Rodrigues A, Vieira AI, Portela F, Cremers I, Cotter J, et al. Review of the disease course among adult ulcerative colitis population-based longitudinal cohorts. Inflamm Bowel Dis. 2012 Mar;18(3):573-83.
8 Safroneeva E, Vavricka S, Fournier N, Seibold F, Mottet C, Nydegger A, et al.; Swiss IBD Cohort Study Group. Systematic analysis of factors associated with progression and regression of ulcerative colitis in 918 patients. Aliment Pharmacol Ther. 2015 Sep;42(5):540-8.

9 Gionchetti P, Amadini C, Rizzello F, Venturi A, Campieri M. Review article: treatment of mild to moderate ulcerative colitis and pouchitis. Aliment Pharmacol Ther. 2002 Jul; 16(s4 Suppl 4):13-9.

10 Safroneeva E, Vavricka SR, Fournier N, Straumann A, Rogler G, Schoepfer AM. Prevalence and Risk Factors for Therapy Escalation in Ulcerative Colitis in the Swiss IBD Cohort Study. Inflamm Bowel Dis. 2015 Jun;21(6): 1348-58.

11 Sandborn WJ, Hanauer SB. Systematic review: the pharmacokinetic profiles of oral mesalazine formulations and mesalazine prodrugs used in the management of ulcerative colitis. Aliment Pharmacol Ther. 2003 Jan; 17(1):29-42.

12 Dignass A, Lindsay JO, Sturm A, Windsor A, Colombel JF, Allez M, et al. Second European evidence-based consensus on the diagnosis and management of ulcerative colitis part 2 : current management. J Crohn's Colitis. 2012 Dec;6(10):991-1030.

13 Frieri G, Pimpo MT, Palumbo GC, Onori L, Viscido A, Latella G, et al. Rectal and colonic mesalazine concentration in ulcerative colitis: oral vs. oral plus topical treatment. Aliment Pharmacol Ther. 1999 Nov;13(11):1413-7.

14 Gionchetti P, Rizzello F, Venturi A, Ferretti $\mathrm{M}$, Brignola C, Miglioli M, et al. Comparison of oral with rectal mesalazine in the treatment of ulcerative proctitis. Dis Colon Rectum. 1998 Jan;41(1):93-7.
15 Marshall JK, Irvine EJ. Rectal corticosteroids versus alternative treatments in ulcerative colitis: a meta-analysis. Gut. 1997 Jun;40(6): 775-81.

16 Campieri M, Gionchetti P, Belluzzi A, Brignola C, Migaldi M, Tabanelli GM, et al. Efficacy of 5-aminosalicylic acid enemas versus hydrocortisone enemas in ulcerative colitis. Dig Dis Sci. 1987 Dec;32(12 Suppl):67S-70S.

17 Cohen RD, Woseth DM, Thisted RA, Hanauer SB. A meta-analysis and overview of the literature on treatment options for left-sided ulcerative colitis and ulcerative proctitis. Am J Gastroenterol. 2000 May;95(5):1263-76.

18 Marshall JK, Thabane M, Steinhart AH, Newman JR, Anand A, Irvine EJ. Rectal 5-aminosalicylic acid for induction of remission in ulcerative colitis. Cochrane Database Syst Rev. 2010 Jan;1:CD004115.

19 Hartmann F, Stein J; BudMesa-Study Group. Clinical trial: controlled, open, randomized multicentre study comparing the effects of treatment on quality of life, safety and efficacy of budesonide or mesalazine enemas in active left-sided ulcerative colitis. Aliment Pharmacol Ther. 2010 Aug;32(3):368-76.

20 Manguso F, Balzano A. Meta-analysis: the efficacy of rectal beclomethasone dipropionate vs. 5 -aminosalicylic acid in mild to moderate distal ulcerative colitis. Aliment Pharmacol Ther. 2007 Jul;26(1):21-9.

21 Marteau P, Probert CS, Lindgren S, Gassul M, Tan TG, Dignass A, et al. Combined oral and enema treatment with Pentasa (mesalazine) is superior to oral therapy alone in patients with extensive mild/moderate active ulcerative colitis: a randomised, double blind, placebo controlled study. Gut. 2005 Jul;54(7): 960-5. 
22 Seibold F, Fournier N, Beglinger C, Mottet C, Pittet V, Rogler G; Swiss IBD cohort study group. Topical therapy is underused in patients with ulcerative colitis. J Crohn's Colitis. 2014 Jan;8(1):56-63.

23 Rufle W, Frühmorgen P, Huber W, Kimmig JM. Budesonid-Schaum als neues Therapieprinzip bei der distalen Colitis ulcerosa im Vergleich mit Mesalazin-Klysmen. Eine offene, kontrollierte, randomisierte und prospektive multizentrische Pilotstudie. Z Gastroenterol. 2000 Apr;38(4):287-93.

24 Zandman DB, Peppercorn MA. Patient considerations in the management of ulcerative colitis: role of once-daily MMX mesalamine. Patient Prefer Adherence. 2009 Nov;3:87-92.

25 Kane S, Huo D, Aikens J, Hanauer S. Medication nonadherence and the outcomes of patients with quiescent ulcerative colitis. Am J Med. 2003 Jan;114(1):39-43.

26 Testa A, Castiglione F, Nardone OM, Colombo GL. Adherence in ulcerative colitis: an overview. Patient Prefer Adherence. 2017 Feb;11:297-303.

27 Ruddell WS, Dickinson RJ, Dixon MF, Axon AT. Treatment of distal ulcerative colitis (proctosigmoiditis) in relapse: comparison of hydrocortisone enemas and rectal hydrocortisone foam. Gut. 1980 Oct;21(10):885-9.

28 Campieri M, Paoluzi P, D’Albasio G, Brunetti G, Pera A, Barbara L. Better quality of therapy with 5-ASA colonic foam in active ulcerative colitis. A multicenter comparative trial with 5-ASA enema. Dig Dis Sci. 1993 Oct; 38(10):1843-50.
29 Reddy SI, Friedman S, Telford JJ, Strate L, Ookubo R, Banks PA. Are patients with inflammatory bowel disease receiving optimal care? Am J Gastroenterol. 2005 Jun;100(6):135761.

30 Bähler C, Vavricka SR, Schoepfer AM, Brüngger B, Reich $\mathrm{O}$. Trends in prevalence, mortality, health care utilization and health care costs of Swiss IBD patients: a claims data based study of the years 2010, 2012 and 2014. BMC Gastroenterol. 2017 Dec;17(1):138.

31 Schoepfer A, Vavricka SR, Brüngger B, Reich O, Blozik E, Bähler C. Systematic analysis of annual health resource utilization and costs in hospitalized patients with inflammatory bowel disease in Switzerland. Eur J Gastroenterol Hepatol. 2018 Aug;30(8):868-75.

32 Huber CA, Szucs TD, Rapold R, Reich O. Identifying patients with chronic conditions using pharmacy data in Switzerland: an updated mapping approach to the classification of medications. BMC Public Health. 2013 Oct;13(1):1030.

33 Hosmer DW, Lemeshow S. Applied logistic regression. 2nd ed. New York: Wiley; 2000. https://doi.org/10.1002/0471722146.

34 Harbord M, Eliakim R, Bettenworth D, Karmiris K, Katsanos K, Kopylov U, et al.; European Crohn's and Colitis Organisation [ECCO]. Third European Evidence-based Consensus on Diagnosis and Management of Ulcerative Colitis. Part 2: current Management. J Crohn's Colitis. 2017 Jul;11(7):76984.

35 Piodi LP, Ulivieri FM, Cermesoni L, Cesana BM. Long-term intermittent treatment with low-dose 5 -aminosalicylic enemas is efficacious for remission maintenance in ulcerative colitis. Scand J Gastroenterol. 2004 Feb;39(2): 154-7.
36 Singh S, Proudfoot JA, Dulai PS, Jairath V, Fumery $\mathrm{M}, \mathrm{Xu} \mathrm{R}$, et al. No Benefit of Concomitant 5-Aminosalicylates in Patients With Ulcerative Colitis Escalated to Biologic Therapy: Pooled Analysis of Individual Participant Data From Clinical Trials. Am J Gastroenterol. 2018 Aug;113(8):1197-205.

37 Farup PG, Hovde O, Halvorsen FA, Raknerud $\mathrm{N}$, Brodin U. Mesalazine suppositories versus hydrocortisone foam in patients with distal ulcerative colitis. A comparison of the efficacy and practicality of two topical treatment regimens. Scand J Gastroenterol. 1995 Feb;30(2): 164-70.

38 Kane SV, Cohen RD, Aikens JE, Hanauer SB. Prevalence of nonadherence with maintenance mesalamine in quiescent ulcerative colitis. Am J Gastroenterol. 2001 Oct;96(10): 2929-33.

39 Kane SV, Brixner D, Rubin DT, Sewitch MJ. The challenge of compliance and persistence: focus on ulcerative colitis. J Manag Care Pharm. 2008 Jan;14(1 Suppl A):s2-12.

40 Bernstein CN, Nabalamba A. Hospitalization, surgery, and readmission rates of IBD in Canada: a population-based study. Am J Gastroenterol. 2006 Jan;101(1):110-8.

41 Sulz MC, Siebert U, Arvandi M, Gothe RM, Wurm J, von Känel R, et al.; Swiss IBD Cohort Study Group. Predictors for hospitalization and outpatient visits in patients with inflammatory bowel disease: results from the Swiss Inflammatory Bowel Disease Cohort Study. Eur J Gastroenterol Hepatol. 2013 Jul;25(7): $790-7$. 